\title{
Relations among L1 Reading, L2 Knowledge, and L2 Reading: Revisiting the Threshold Hypothesis
}

\author{
Gi-Pyo Park ${ }^{1}$ \\ ${ }^{1}$ Department of English Language and Literature, Soonchunhyang University, Korea \\ Correspondence: Gi-Pyo Park, Department of English Language and Literature, Soonchunhyang University, \\ Korea. E-mail: gipyop@sch.ac.kr
}

$\begin{array}{ll}\text { Received: August 9, } 2013 & \text { Accepted: October 1, } 2013 \quad \text { Online Published: November 5, } 2013 \\ \text { doi:10.5539/elt.v6n12p38 } & \text { URL: http://dx.doi.org/10.5539/elt.v6n12p38 }\end{array}$

\begin{abstract}
This study attempted to test the threshold hypothesis in second/foreign language (L2) reading by investigating the relations among first language (L1) reading, L2 knowledge, and L2 reading comprehension in a sample of 2666 (1333 males and 1333 females) Korean EFL high school students. Three different methods of data analysis were utilized after closely looking into the methods of data analysis of the current literature on a language threshold. Statistical analysis revealed that the contribution of L1 reading and L2 knowledge to L2 reading was significant and substantial in the main and interaction effects, accounting for 54 percent of variance of L2 reading comprehension in tandem. However, the correlation of L1 reading to L2 reading showed, in general, a decreasing trend in accordance with the improvement of L2 knowledge, which is in contrast with the notion of a threshold level. This result of a language threshold was discussed in terms of a broad construct of language transfer and the interactive approach to reading in an L2.
\end{abstract}

Keywords: the threshold hypothesis, first language reading, second language reading, linguistic knowledge

\section{Introduction}

Since the trailblazing research on the linguistic threshold hypothesis to investigate the influence of bilingualism on cognitive development and academic success (Cummins, 1979), attempts have been made to determine whether L1 reading ability can be transferred to L2 reading ability. The transferability of L1 reading to L2 reading has been discussed with the center of the short-circuit hypothesis or the threshold hypothesis (Alderson, 1984; Clarke, 1980).

Regardless of the crucial importance of the threshold hypothesis in L2 reading, empirical studies to test the hypothesis have been regrettably limited and the findings, to date, have been surprisingly conflicted each other (Ardasheva et al., 2011; August, 2006; Bernhardt \& Kamil, 1995; Bossers, 1991; Carrell, 1991; Jiang, 2011; Lee \& Schallert, 1997; Park \& Chae, 2000; Pichette et al., 2003; Taillefer, 1996). The conflicting findings might be in part attributable to L2 readers' native language that was intricately interwoven with other confounding variables including proficiency level, reading task, and learning context, and in part attributable to the lack of research methods used to test the hypothesis. Thus, more studies should be undertaken to shed further light on how skills and strategies of L1 reading transfer to L2 reading by using more complete research methods among L2 learners of different L1, at different proficiency levels, and in different learning contexts.

The main purpose of the present study was to test the threshold hypothesis by calculating the relations of L1 reading, L2 knowledge, and L2 reading comprehension according to various L2 knowledge levels among English as a Foreign Language (EFL) learners in Korea. Another purpose was to classify previous studies on a threshold level based on the methods of data analysis and interpretation which have often been the center of conflicting findings. The following three research questions were raised to guide the study:

(1) What is the influence of L1 reading and L2 knowledge in L2 reading comprehension for the whole group?

(2) Is the influence of L1 reading and L2 knowledge in L2 reading comprehension different when the whole group is divided into two groups according to L2 knowledge?

(3) What are the correlations between L1 reading and L2 reading at seven different L2 knowledge levels? 


\section{Background}

Cummins (1979) proposed the threshold hypothesis in bilingualism which holds that a bilingual child's linguistic competence mediates the effect of his or her cognitive development and bilingual learning. Extrapolating this notion to L2 reading comprehension, Alderson (1984) contended that "Poor foreign language reading is due to reading strategies in the first language not being employed in the foreign language, due to inadequate knowledge of the foreign language." (p. 4) In other words, lack of L2 linguistic knowledge "short circuits," or interferes with transferring well developed L1 strategic knowledge to L2 reading comprehension (Clarke, 1980).

In order to investigate the notion of the threshold hypothesis, researchers have entertained the idea of a "reading problem" or a "language problem" as a way of understanding L2 reading (Alderson, 1984; Carrell, 1991). Three different methods of data analysis and interpretation have been utilized to examine the existence of the hypothesis. The first method is to investigate the relative importance of L1 reading and L2 knowledge in L2 reading comprehension by performing regression analysis using the whole group of the sample. The contention is that the role of L2 knowledge should be significant in L2 reading and be bigger than that of L1 reading in L2 reading comprehension to support the threshold hypothesis. Otherwise, the data may support the linguistic interdependent hypothesis which posits that L2 reading is like L1 reading at the fundamental core because knowledge of L1 reading can be transferred to L2 reading across L2 proficiency levels (Alderson, 1984; August, 2006; Bernhardt \& Kamil, 1995; Carrell, 1991; Jiang, 2011). Of note is that the first method of data analysis and interpretation provides only the potential existence of a threshold level, with no indication of a hypothetical threshold level in L2 reading, let alone an actual level of a language threshold. The contribution of L1 reading and L2 knowledge to L2 reading in this method of investigating the threshold hypothesis can be schematized as the following formula:

\section{(1) L2 knowledge > L1 reading}

One of the positive evidences to a language threshold was provided by Bernhardt and Kamil (1995) who examined the contribution of English reading to Spanish reading according to the amount of exposure to the second language in a sample of 187 college students learning Spanish in the USA. The students were at three different levels of Spanish: beginning, intermediate, and advanced levels. Results showed that even though both English reading and Spanish level contributed to Spanish reading comprehension significantly, Spanish levels contributed to Spanish reading more than English reading did, with the total variance of 48 percent in Spanish reading comprehension.

More recently, Jiang (2011) investigated L2 reading comprehension ability as a function of L1 literacy and L2 proficiency among 246 Chinese EFL university students. L1 literacy and L2 proficiency were determined by the Chinese and English subtests of college entrance exam, whereas L2 reading ability was measured by the reading comprehension section of the Test of English as a Foreign Language (TOEFL) and an English passage developed by the author. Results showed that Chinese literacy and English proficiency together accounted for 27 percent of variance of TOEFL reading comprehension and 40 percent of variance of English passage, and that English proficiency was more contributive to the TOEFL and the author-developed English passage than Chinese literacy, supporting the threshold hypothesis.

Other studies were not in line with a language threshold level. For instance, by introducing the insightful formula of "L2 reading = L1 reading + L2 proficiency level," Carrell (1991) investigated the role of reading ability and language proficiency in L2 reading comprehension using 45 English learners of Spanish speakers in levels 3, 4, and 6, and 75 Spanish learners of English speakers in levels 2, 3, and 4. Each group was asked to answer multiple choice questions after reading two English reading passages and two Spanish reading passages. The results of data analysis showed that the roles of the regressors were significant in L2 reading comprehension, explaining about 35 percent of the dependent variable for the Spanish L1 group and about 53 percent of the dependent variable for the English L1 group. In addition, L2 proficiency was more contributive to L2 reading comprehension than L1 reading ability for the English L1 group. However, for the Spanish L1 group, the reverse was true. That is, L1 reading ability was more contributive to L2 reading comprehension than L2 proficiency, providing conflicting evidence concerning a threshold level.

In a study investigating the relations of L1 reading to L2 reading and L2 grammar to L2 reading among 55 native Spanish-speaking ESL students in college, August (2006) found the significant correlations between variables with the coefficients ranged between .309 and .341. In a simple regression, the contribution of L1 reading to L2 reading was slightly bigger than the contribution of L2 grammar to L2 reading, supporting the linguistic interdependence hypothesis rather than the threshold hypothesis. In short, the contribution of L1 reading and L2 knowledge to L2 reading comprehension using the whole group of the sample provided conflicting findings in 
relation to the threshold hypothesis.

The second method of testing the threshold hypothesis is to investigate the relative importance of L1 reading ability and L2 knowledge in L2 reading comprehension by performing regression analysis at two different levels (Bossers, 1991; Park \& Chae, 2000; Pichette et al., 2003; Taillefer, 1996). The threshold hypothesis will be supported if L1 reading plays a prominent role in L2 reading for the high proficient L2 readers, but L2 knowledge plays a prominent role in L2 reading for the low proficient L2 readers. This contention is schematized as the following formula:

(2) The low proficiency group: L1 reading $<$ L2 knowledge

The high proficiency group: L1 reading $>$ L2 knowledge

Other possible combinations of relations between these two variables at the low and high proficiency groups are not consistent with the threshold hypothesis. The problem with this method is that even though this method of data analysis and interpretation reveals a hypothetical threshold level, it fails to reveal more specifically where an actual threshold level is in the continuum from the lowest to the highest level of L2 proficiency.

One of the positive evidences to the threshold hypothesis was found by Bossers (1991) who examined the relations among L1 reading ability, L2 knowledge, and L2 reading comprehension in a sample of 50 native speakers of Turkish learning Dutch as a second language. He found that for the least skilled L2 readers, only L2 knowledge significantly contributed to L2 reading comprehension, together accounting for 46 percent of variance of L2 reading comprehension. However, for the most skilled readers, only L1 reading significantly contributed to L2 reading, together accounting for 34 percent of variance of the dependent variable.

Another positive evidence pertaining to a language threshold was provided by Pichette et al. (2003) who investigated whether L1 reading skills have to be kept active if these skills are to be transferred to L2 reading comprehension using 52 Bosnians learning French as an L2. In a longitudinal study for a period of one year at Time 1 and Time 2, they found that the contribution of L2 knowledge to L2 reading was dominant at Time 1, and that the contribution of L1 reading was dominant at Time 2, supporting the threshold hypothesis. Another interesting finding of this study was that maintaining L1 reading enhanced the transfer of L1 reading skills and strategies.

Regardless of the aforementioned positive evidence to a language threshold, negative evidence to the hypothesis was also found. Taillefer (1996) examined the interaction of L1 reading and L2 proficiency in L2 reading comprehension among 53 EFL university students in France who were divided into two groups by L2 proficiency. L1 and L2 reading comprehension scores were measured by relatively easy scanning exercises and difficult receptive reading exercises, whereas L2 proficiency was determined by the grammar and vocabulary sections of the TOEFL and a cloze test. Statistical analysis showed that the role of L2 proficiency in L2 reading was bigger than that of L1 reading in L2 reading in receptive reading exercises for the high L2 group, but that the role of L1 reading in L2 reading was bigger than that of L2 proficiency in L2 reading in scanning exercises for the high L2 group. The roles of L1 reading and L2 proficiency in L2 reading were not statistically significant in the receptive and scanning exercises for the low L2 group, providing evidence that was not in accord with the threshold hypothesis.

Additional negative evidence was provided by Park and Chae (2000) who examined the contribution of L1 reading ability and L2 proficiency to L2 reading comprehension using 340 Korean EFL high school students who were divided into two groups based on L2 knowledge measured by knowledge of grammar and vocabulary. L1 and L2 reading comprehension was determined by the Korean and English subtests of the practice version of the Korea College Scholastic Ability Test. Results showed that both independent variables together explained 30 percent of variance of English reading comprehension, and that English reading comprehension owed more to English knowledge than to Korean reading ability. In short, the second method of examining the threshold hypothesis identified by two different levels of L2 proficiency provided contradictory results of the possible transfer of $\mathrm{L} 1$ reading to $\mathrm{L} 2$ reading beyond a hypothetical language threshold.

The third method of testing the threshold hypothesis is to calculate the correlations between L1 and L2 reading comprehension at various levels of L2 proficiency. This method assumes that the correlations between these two variables are higher above a threshold level, but lower below a threshold level, as summarized in the following formula:

(3) Below a threshold level: Low correlations between L1 and L2 reading

Above a threshold level: High correlations between L1 and L2 reading 
This method of data analysis and interpretation is more complete than the previous two methods because it can reveal where an actual threshold level is, a focal point of research in the threshold hypothesis. Nevertheless, the potential drawback is that this method requires a large number of participants to divide the whole group into several levels, say, seven or ten, of L2 proficiency.

The only study that utilized the third way of data analysis was undertaken by Lee and Schallert (1997) who investigated the correlation between L1 and L2 reading in a sample of 809 EFL middle school and high school students in Korea. Both the Korean reading test and English reading test consisted of two descriptive and two expository passages selected from the mock tests issued by the Educational Research Center in Korea and the Metropolitan Achievement Test, respectively, whereas the English Proficiency Test measured the participants' knowledge of vocabulary and grammar. The results of the Pearson product moment correlation revealed that the correlations between L1 and L2 ranged between .09 and .22 below a threshold level, but ranged between .34 and .37 above the level. The result of this study is what is summarized in the formula (3) above, providing positive evidence to the threshold hypothesis.

Overall, research efforts have been made to investigate the threshold hypothesis which holds the transferability of strategic knowledge of L1 reading to L2 reading beyond a threshold level, utilizing different methods of data analysis and interpretation. However, the results of previous studies have shown conflicting results across studies undertaken by using L2 learners of different L1, at different proficiency levels, and in different learning contexts. The notion of a language threshold should be taken into consideration under the notion of language transfer which consists of positive transfer and negative transfer (Brown, 2007a; Ellis, 2008). Then, more studies should be conducted using more complete methods to understand how L2 learners of different L1 and L2 proficiency transfer strategic knowledge of L1 reading to L2 reading comprehension in different learning contexts.

\section{Methods}

\subsection{Participants}

A total of 2666 high school students, who applied to a university in Korea, were used as participants of this study. The participants were aged 19 on average and consisted of 1333 males and 1333 females. They were randomly selected from 7098 applicants who took the tests of Korean reading, English reading, and mathematics in order to enter the university.

At the time the participants applied to the university, they had studied English in public school for a composite of 10 years: six years in secondary school for about three to four hours per week and four years in elementary school for about one hour per week. It should be noted that in consideration of the prestige of the university, the participants' level of Korean reading, English knowledge, and English reading was presumably above the norm. Nevertheless, it was assumed that the participants would show individual differences in these subjects depending on the time and efforts they had invested both inside and outside the classroom (Hong-Nam \& Leavell, 2007).

\subsection{Instruments}

Three research instruments developed to screen out students who applied to a university were used to collect the data: The Korean reading test, the English reading test, and the English knowledge test. These tests were developed by test specialists consisting of six professors and two high school teachers in a special task for two weeks. In developing test items, the test specialists were advised to consider the high school curriculum of each subject as well as the examinees' Korean and English reading comprehension levels which were presumed above the norm compared with other high school seniors.

The Korean and English reading tests were chosen for this study because there were similarities in these two tests pertaining to item numbers and items types. Each of these tests consisted of 50 items covering four item types: Vocabulary, grammar, factual information, and inferential information. More specifically, the Korean reading test consisted of 6 items of vocabulary, 9 items of grammar, 5 items of factual information, and 30 items of inferential items, whereas the English reading test was comprised of 10 items of vocabulary, 5 items of grammar, 8 items of factual information, and 27 items of inferential information.

It should be noted that out of the 50 items in the English reading comprehension test, only 35 items were used to determine students' English reading comprehension ability. The other 15 items which were developed to measure English vocabulary and English grammar were used to measure students' English knowledge, as per the recommendation of other researchers who attempted to examine a language threshold (Lee \& Schallert, 1997; Pichette et al., 2003). All the three instruments were measured using multiple choice questions because regardless of a potential validity problem of a multiple choice question, it has advantage over other methods of testing in terms of reliability, being most commonly used worldwide in a reading comprehension test (Carrell, 
1991; Salkind, 2006).

\subsection{Data Collection and Data Analysis}

The author contacted the university staff in charge of developing both the Korean and English reading comprehension tests, explained the purpose of this study, and asked for the data. After getting allowance from a university meeting, the university staff transmitted the data to the author on condition that the name of the university should be anonymous, and that the data should be used for research purposes only. After obtaining the data, the author closely examined the data, excluded any data that contained missing information, and randomly chose 2666 data with 1333 males and 1333 females. The data were analyzed by performing Pearson product-moment correlations and regression analyses using SPSS 19.

\section{Results}

The statistical analysis of the main variables was performed from various angles with the center on research questions raised above. In order to contextualize the results of data analysis, the mean scores and standard deviations of the variables of the whole group were calculated and reported in Table 1. The English reading test was more difficult $(\mathrm{m}=42.00$ out of 70$)$ and highly dispersed $(\mathrm{SD}=10.87)$ than the Korean reading test $(\mathrm{m}=69.93$ out of $100 ; \mathrm{SD}=9.837$ ). The mean score and standard deviation of English knowledge as determined by the scores of vocabulary and grammar were 16.38 and 5.780, respectively. Considering the mean scores and standard deviations of all the variables, these scores were considered variable enough for subsequent statistical analyses.

In an answer to Research Question 1, a regression analysis was performed using the whole group of the sample $(\mathrm{n}=2666)$ with Korean reading ability and English knowledge as regressors, or independent variables, and English reading ability as a dependent variable. Table 2 shows that the regressors of Korean reading ability and English knowledge contributed to English reading comprehension ability significantly $(F=1553.970 ; p<.001)$, together accounting for about 54 percent of variance of English reading ability. In addition, the contribution of English knowledge $(t=30.548, p<.001)$ to English reading was significant and outweighed the contribution of Korean reading $(t=24.048, p<.001)$ to English reading for the whole group, with the significant interaction effects between these two independent variables on English reading $(F=16.695 ; p<.001)$.

Table 1. Means and standard deviations of the variables for the whole group

\begin{tabular}{llll}
\hline Group (n) & Variables & Mean & SD \\
\hline \multirow{3}{*}{ Whole (2666) } & Korean Reading & 69.9 & 9.8 \\
& English Knowledge & 16.4 & 5.8 \\
& English Reading & 42.0 & 10.9 \\
\hline
\end{tabular}

Note: The full scores of each test from top to bottom were 100, 30, and 70 .

Table 2. Regression and ANOVA: influence of Korean reading ability and English knowledge in English reading ability

\begin{tabular}{llllllll}
\hline Group (n) & Variables & Beta & $t$ & $p$ & Adjusted $R^{2}$ & $F$ & $p$ \\
\hline \multirow{2}{*}{ Whole(2666) } & Korean Reading & .370 & 24.038 & .000 & \multirow{2}{*}{.538} & \multirow{2}{*}{1553.970} & .000 \\
& English Knowledge & .470 & 30.548 & .000 & & & \\
\hline
\end{tabular}

In order to answer Research Question 2, a regression analysis was run again as Korean reading ability and English knowledge as regressors and English reading ability as a dependent variable at two different levels. The students' level of English reading comprehension was divided into two groups-the low group and the high group-to investigate the roles of Korean reading ability and English knowledge in English reading comprehension. The English reading score of 41 was chosen to divide the whole group. That is, those who scored lower than 41 out of 70 of English reading comprehension were considered as the low group of English reading, whereas those who scored higher than 41 were considered as the high group. The mean scores and standard deviations of variables of the low and high groups of English reading comprehension and the result of a regression analysis of the two groups are shown in Table 3 and Table 4. In both groups, the roles of Korean reading ability and English knowledge were significant, explaining about $36(F=325, p<.001)$ percent and 22 percent $(F=209, p<.001)$ of variances of English reading comprehension for the low and high groups. Interestingly, the contribution of Korean reading ability $(t=15.961, p<.001)$ to English reading comprehension 
was significant and bigger than that of English knowledge $(t=12.032, p<.001)$ for the low group of English reading. Conversely, however, the contribution of English knowledge $(t=16.488, p<.001)$ to English reading comprehension was more significant and bigger than that of Korean reading ability $(t=6.689, p<.001)$ for the high group of English reading. That is, the contribution of Korean reading to English reading was getting smaller, whereas the contribution of English knowledge to English reading was getting bigger when English knowledge improved.

Table 3. Means and SDs of the variables of the low and high levels of English reading ability

\begin{tabular}{llll}
\hline Group (n) & Variables & Mean & SD \\
\hline \multirow{3}{*}{ Low (1147) } & Korean Reading & 64.4 & 10.3 \\
& English Knowledge & 12.8 & 5.2 \\
& English Reading & 31.8 & 7.2 \\
\hline \multirow{3}{*}{ High (1519) } & Korean Reading & 74.1 & 7.0 \\
& English Knowledge & 19.1 & 4.6 \\
& English Reading & 49.7 & 5.5 \\
\hline
\end{tabular}

Table 4. Regression and ANOVA: influence of Korean reading ability and English knowledge in the low and high levels of English reading ability

\begin{tabular}{llllllll}
\hline Group (n) & Variables & Beta & $t$ & $p$ & Adjusted $R^{2}$ & $F$ & $p$ \\
\hline \multirow{2}{*}{ Low (1147) } & Korean Reading & .410 & 15.961 & .000 & .361 & 325.261 & .000 \\
& English Knowledge & .309 & 12.032 & .000 & & & \\
\hline \multirow{2}{*}{ Hig (1519) } & Korean Reading & .159 & 6.689 & .000 & .215 & 209.209 & .000 \\
& English Knowledge & .392 & 16.488 & .000 & & & \\
\hline
\end{tabular}

In an answer to Research Question 3, the correlations between English reading ability and Korean reading ability at various levels of English knowledge were investigated. For this investigation, the participants were divided into seven subgroups (G1 - G7) according to their English knowledge levels. Specific care was taken in dividing the groups because the results of subsequent data analysis were partly subject to the ways of group division. Every increment of four points of English knowledge was chosen in group division except the lowest group (G1) and the highest group (G7), where six-point increments were chosen because of the relatively limited number of the participants in these two groups. Table 5 shows the mean scores and standard deviations of the seven groups, followed by the correlations between Korean reading ability and English reading ability of each group. Even though the correlations between these two variables were significant in all the groups $(p<.05)$, the correlation coefficients became, in general, smaller when English knowledge level increased. These correlations between Korean reading and English reading are graphically displayed in Figure 1.

Table 5. Scores of English knowledge and correlations between Korean and English reading at different groups

\begin{tabular}{llll}
\hline Group(n) & $\begin{array}{l}\text { English Knowledge } \\
\text { M (SD) }\end{array}$ & $\begin{array}{l}\text { Correlations between } \\
\text { Korean and English Reading }\end{array}$ & $p$ \\
\hline G1 (78) & $3.39(1.084)$ & .434 & .000 \\
G2 (238) & $7.29(0.960)$ & .568 & .000 \\
G3 (449) & $11.09(0.997)$ & .519 & .000 \\
G4 (608) & $15.10(0.996)$ & .476 & .000 \\
G5 (665) & $18.99(1.001)$ & .319 & .000 \\
G6 (493) & $22.81(0.982)$ & .297 & .000 \\
G7 (135) & $26.92(1.310)$ & .209 & .015 \\
\hline
\end{tabular}




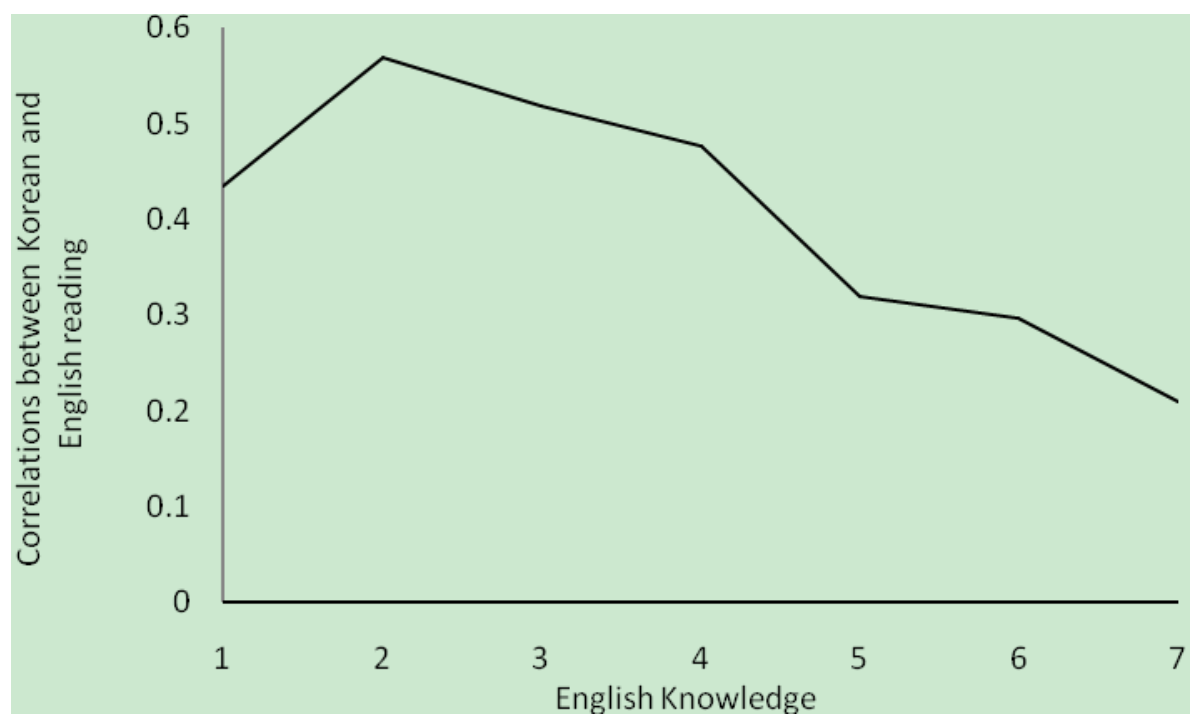

Figure 1. Correlations between Korean reading and English reading at different groups of English knowledge

\section{Discussion}

One of the findings of the present study that investigates the threshold hypothesis in L2 reading was made by analyzing the data using the whole group of the sample. Both regressors, L1 reading and L2 knowledge, played significant roles in the criterion variable of L2 reading comprehension, accounting for about 54 percent of the variance of the criterion variable in tandem. This shared variance between the regressors and the criterion variable provided evidence that $\mathrm{L} 2$ reading comprehension was a function of $\mathrm{L} 1$ reading and L2 knowledge. In addition, the contribution of L2 knowledge to L2 reading comprehension was bigger than that of L1 reading when the data were analyzed among the whole group. This finding is consistent with the aforementioned first formula schematized as following and supporting the threshold hypothesis:

(1) L2 knowledge $>$ L1 reading

The finding of this study is consistent with some studies where the contribution of L2 knowledge to L2 reading was bigger than the contribution of L1 reading to L2 reading (Bernhardt \& Kamil, 1995; Jiang, 2011). Researchers contended that when the contribution of L2 knowledge to L2 reading is bigger than the contribution of L1 to L2 reading, the threshold hypothesis is supported in comparison with the linguistic interdependence hypothesis where the role of $\mathrm{L} 1$ reading in $\mathrm{L} 2$ reading comprehension is bigger than the role of L2 knowledge in L2 reading (August, 2006; Bernhardt \& Kamil, 1995). However, care must be taken before making a hasty conclusion because the idea of the significant and dominant contribution of L2 knowledge to L2 reading comprehension is necessary, but not sufficient to support the threshold hypothesis. When the data are analyzed using the whole group of the sample, it provides no evidence about a hypothetical threshold level, not to mention an actual threshold level which is a fundamental and crucial point of discussion of the threshold hypothesis.

Another finding of this study was made possible by analyzing the data using two groups of the sample based on L2 reading. For the low level of L2 reading, the importance of L1 reading outweighed that of L2 knowledge in L2 reading comprehension. Conversely, however, the importance of L2 knowledge outweighed that of L1 reading for the high level of L2 reading. This finding is unique and distinct from other studies conducted by dividing the whole group into two levels of L2 knowledge or L2 reading (Bossers, 1991; Park \& Chae, 2000; Pichette et al., 2003; Taillefer, 1996). In spite of the theoretical insight of the threshold hypothesis which holds that poor L2 reading is due to poor L2 knowledge which short circuits L1 reading, the empirical finding of this study is not in line with the second formula which is schematized as following:

(2) The low proficiency group: L1 reading $<$ L2 knowledge

The high proficiency group: L1 reading $>$ L2 knowledge

The potential problem of data analysis and interpretation by analyzing the data using two levels of the sample is that even though the data reveal a hypothetical threshold level, the data do not reveal an actual threshold level because the level is chosen arbitrarily. In other words, the arbitrary division of a variable on the basis of L2 knowledge (Park \& Chae, 2000; Pichette et al., 2003) or L2 reading (Bossers, 1991; Taillefer, 1996) will not 
reveal where an actual threshold level is. Furthermore, caution should be exercised in the interpretation of the results of data analysis because when dividing a variable into two, the variance of the divided variable, say, L2 knowledge or L2 reading, will be cut in half, which will limit the variance explained by the regressors and the criterion variable.

A third finding of this study was made by dividing the whole group into seven groups on the basis of L2 knowledge level. The finding was that the correlations between $\mathrm{L} 1$ reading and $\mathrm{L} 2$ reading showed, in general, a decreasing trend rather than an increasing trend according to the improvement of L2 knowledge. This finding is in contrast with a previous finding (Lee \& Schallert, 1997) and the third formula schematized as following:

(3) Below a threshold level: Low correlations between L1 and L2 reading

Above a threshold level: High correlations between L1 and L2 reading

Worthy of note is that calculating the correlations between L1 and L2 reading at various levels of linguistic knowledge is a better method than performing regression analysis using either a whole sample or two-group samples. The reason is that it can be better understood where an actual threshold level of L2 reading falls by calculating the correlations of L1 and L2 reading in the continuum of L2 knowledge level from the lowest to the highest.

Given the findings of the present study, it is safe to conclude that contrary to the first finding of the present study, the threshold hypothesis in L2 reading comprehension was not supported. The next question is to speculate the potential reasons for debunking the notion of a threshold level which is crucial to understanding how L2 readers take advantage of their L1 reading and L2 knowledge in L2 reading. The best speculation is that the notion of the threshold hypothesis may not be applied to a situation where L1 and L2 is noticeably different from each other in linguistic systems including orthography, vocabulary, pronunciation, syntax, and discourse. That is, Korean and English are so different in linguistic systems that Korean students' well-developed Korean reading skills and strategies may not be as transferrable to English reading as may other English learners' native language reading skills and strategies. In this sense, the notion of the threshold hypothesis should be understood under the more general construct of language transfer which consists of positive transfer and negative transfer, or interference (Brown, 2007a; Ellis, 2008). Positive transfer occurs when previous knowledge contributes to subsequent performances, while negative transfer occurs when previous knowledge impedes subsequent performances. When students of L1, which is different from L2 in linguistic systems, read L2 texts, negative transfer rather than positive transfer may occur and strategic knowledge of L1 reading may not transfer to subsequent performances of L2 reading. Thus, contrary to the findings by Lee and Schallert (1997), it is not surprising to discover that the findings of this and other studies provided negative evidences to a language threshold which may be relative and subject to other variables (Park \& Chae, 2000; Takakuwa, 2005).

Nevertheless, it is surprising to find that the correlations between L1 reading and L2 reading showed, in general, a decreasing trend rather than an increasing trend as the level of linguistic knowledge improved. This might be because the contribution of linguistic knowledge to L2 reading improved in accordance with the improvement of L2 knowledge, as shown in the dominant role of L2 knowledge in L2 reading for the high group in Table 4 and the significant interaction effect between L1 reading and L2 knowledge in the $F$-statistic. This finding supports the interactive model of L2 reading which posits that L2 readers use both the schema-driven top-down approach and the language-driven bottom-up approach in the processing of L2 text, and that L2 reader's schema and L2 knowledge are compensating for each other when necessary in reading in an L2 (Brown, 2007b; Stanovich, 1984). Thus, the decreasing correlations between L1 reading and L2 reading according to the improvement of L2 knowledge might be due to the decreasing role of L1 reading in L2 reading, which might be compensated for by the increasing role of $\mathrm{L} 2$ knowledge in $\mathrm{L} 2$ reading.

\section{Conclusion}

This study explored the threshold hypothesis in L2 reading comprehension and made several important findings which provided theoretical and practical implications. Theoretically, regardless of the theoretical insight of the threshold hypothesis on L2 reading, the data of this study did not support the threshold hypothesis. The reason for the rejection might be that a threshold level was subject to many variables including the similarity between L1 and L2 in linguistic systems. This variable together with other confounding variables including L2 proficiency level, the difficulty level of a task, and learning context would interact with each other and influence a threshold level. What makes more complex about a language threshold is that it is relative rather than absolute with various threshold levels in L2 reading depending on aforementioned several variables, which makes the results of research inconsistent and unpredictable (Cummins, 1979; Takakuwa, 2005). Practically, in spite of the negative evidence to the notion of a threshold level, L1 reading and L2 knowledge exerted significant roles in L2 
reading comprehension. Thus, language teachers should teach L2 reading comprehension in the classroom with an emphasis on language-based approaches and strategy-based approaches which are in interactive and compensatory relations. How language teachers should teach reading comprehension on the basis of these approaches to L2 reading is beyond the scope of this study, but these approaches are well documented in the literature of teaching L2 reading skills (Brown, 2007b).

Regardless of the important findings and implications, the present study has limitations concerning two points. First, the findings of the present study were made by analyzing the data collected among Korean EFL high school students, and thus generalizing these findings to other learners of different native language, different proficiency levels, and different learning contexts should be made with caution. Second, the participants' English reading proficiency of the present study was presumably above the norm, but their English proficiency was unclear because they did not take a standardized English proficiency test. Thus, more studies on a language threshold in L2 reading comprehension should be undertaken across native language, proficiency level, and learning context until consistent and replicable findings are made.

\section{Acknowledgements}

Role of the Funding: This work was supported in part by the Soonchunhyang University Research Fund. I would like to thank Mr. Joong-Sung Shin and Ms. Suk Kyung Kim for their assistance in data collection and coding.

\section{References}

Alderson, J. C. (1984). Reading: A reading problem or a language problem? In J. C. Alderson, \& A. H. Uraquhart (Eds.), Reading in a foreign language (pp. 1-24). Essex, UK: Longman.

Ardasheva, Y., Tretter, T. R., \& Kinny, M. (2011). English language learners and academic achievement: Revisiting the threshold hypothesis. Language Learning, 5, 1-44.

August, G. (2006). So, what's behind adult English second language reading? Bilingual Research Journal, 30, 245-264.

Bernhardt, E., \& Kamil, M. (1995). Interpreting relationships between L1 and L2 reading: Consolidating the linguistic threshold and the linguistic interdependence hypothesis. Applied Linguistics, 16, 15-34.

Bossers, B. (1991). On thresholds, ceilings, and short-circuits: The relation between L1 reading, L2 reading and L2 knowledge. In J. H. Julstijn, \& J. F. Matters (Eds.), AILA Review, 8, 45-60.

Brown, D. (2007a). Principle of language learning and teaching (5th ed.). White plains, NY: Pearson Education.

Brown, D. (2007b). Teaching by principles: An interactive approach to language pedagogy (3rd ed.). White Plains, NY: Pearson Education.

Carrell, P. (1991). Second language reading: Reading ability or language proficiency? Applied Linguistics, 12, 159-179.

Clarke, M. (1980). The short circuit hypothesis of ESL reading or when language competence interferes with reading performance. Modern Language Journal, 64, 203-209.

Cummins, J. (1979). Linguistic interdependence and educational development of bilingual children. Review of Educational Research, 49, 222-251.

Ellis, R. (2008). The study of second language acquisition (2nd ed.). Oxford: Oxford University Press.

Hong-Nam, K., \& Leavell, A. G. (2006). Language learning strategy use of ESL students in an intensive English learning context. System, 34, 399-415.

Jiang, X. (2011). The role of first language literacy and second language proficiency in second language reading comprehension. The Reading Matrix, 11, 177-190.

Lee, J. W., \& Schallert, D. L. (1997). The relative contribution of L2 language proficiency and L1 reading ability to L2 reading performance: A test of the threshold hypothesis in an EFL context. TESOL Quarterly, 31, 713-739.

Park, G. P., \& Chae, J. S. (2000). Testing the threshold hypothesis in foreign language reading. Foreign Languages Education, 7, 259-276.

Pichette, F., Segalowitz, N., \& Connors, K. (2003). Impact of maintaining L1 reading skills on L2 reading skill development in adults: Evidence from speakers of Serbo-Croatian learning French. Modern Language Journal, 87, 391-403. 
Salkind, N. J. (2006). Exploring research (6th ed.). Upper Saddle River, NJ: Pearson Prentice Hall.

Stanovich, K. E. (1984). The interactive compensatory model of reading: A confluence of developmental, experimental, and educational psychology. Remedial and Special Education, 5, 11-19.

Takakuwa, M. (2005). Lessons from a paradoxical hypothesis: A methodological critique of the threshold hypothesis. In J. Cohen, K. T. McAlister, K. Rolstad, \& J. JacSwan (Eds.), ISB4: Proceedings of the $4^{\text {th }}$ international symposium on bilingualism (pp. 2222-2232). Somerville, MA: Cascadilla Press.

Taillefer, G. F. (1996). L2 reading ability: Further insight into the short-circuit hypothesis. Modern Language Journal, 80, 461-477.

\section{Copyrights}

Copyright for this article is retained by the author(s), with first publication rights granted to the journal.

This is an open-access article distributed under the terms and conditions of the Creative Commons Attribution license (http://creativecommons.org/licenses/by/3.0/). 